
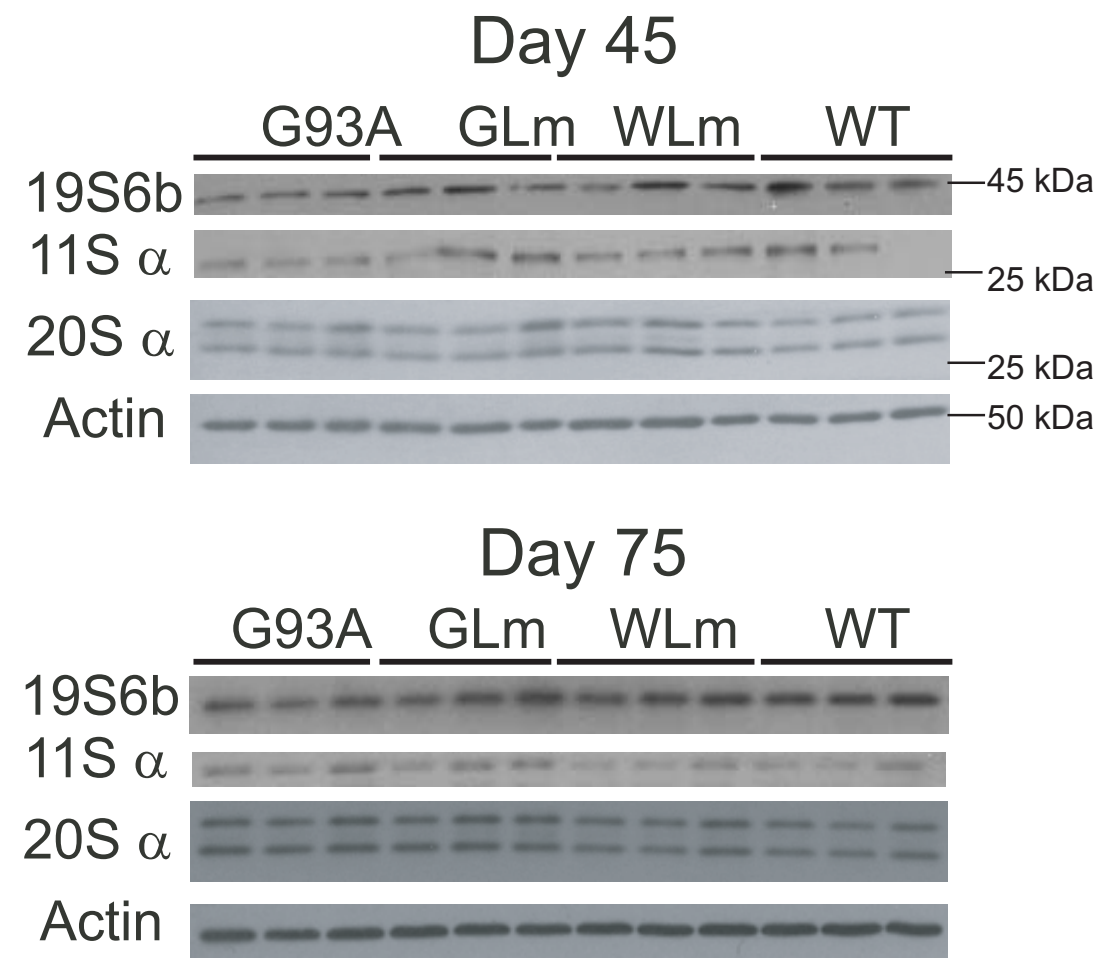

(b)

\title{
Thoracic Spinal Cord
}

Day 45

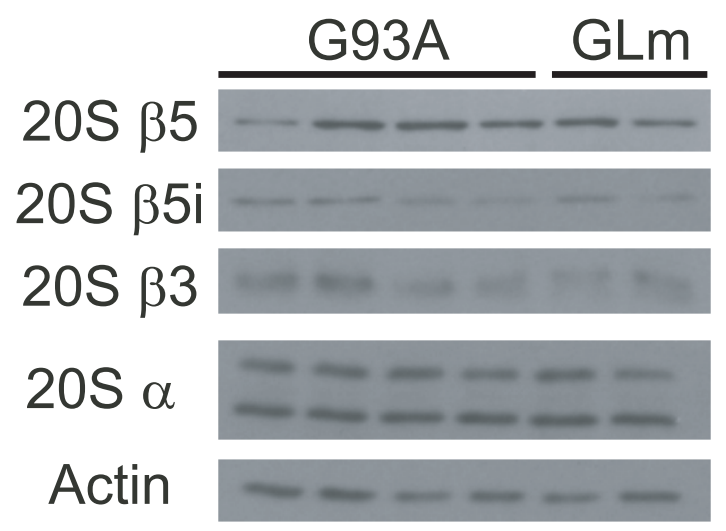

Day 75

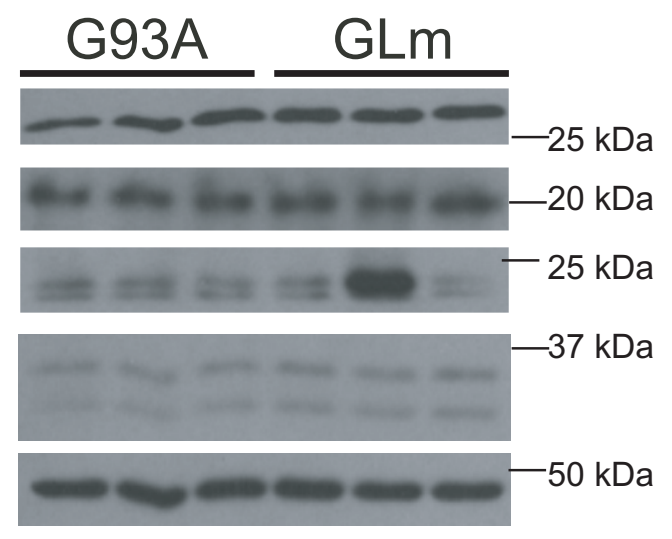

Fig. S3 (a) Levels of $1956 b$ and $11 S \alpha$ regulatory subunits were unchanged in lumbar spinal cord of P45 and P75 SOD1G93A transgenic mice compared to their nontransgenic littermates (GLm). Shown are Western blots of data presented in Fig. $1 \mathrm{c}, \mathrm{d}$ ). (b) There was no significant difference in levels of any subunit tested in extracts of thoracic spinal cord from SOD1G93A (shown are Western blots of data presented in Fig. 1 e,f). 